\title{
Expansion of Myeloid-Derived Suppressor Cells in Patients with Acute Coronary Syndrome
}

\author{
Yan-ge Wang ${ }^{\mathrm{a}}$ Xin Xiong ${ }^{\mathrm{a}}$ Zhu-yue Chen ${ }^{\mathrm{a}}$ Kan-ling Liu ${ }^{\mathrm{b}}$ Jin-hua Yang ${ }^{\mathrm{a}}$ \\ Qiang Wen ${ }^{a}$ Fang-qin $\mathrm{Wu}^{\mathrm{a}}$ Xiao-fan $\mathrm{Hu}^{\mathrm{a}}$ Yu-dong Peng ${ }^{\mathrm{a}}$ Jing-jing $\mathrm{Wu}^{\mathrm{a}}$ \\ Yi-tian Lian ${ }^{a}$ Wen-cai Zhang ${ }^{a, c}$ Long-xian Cheng ${ }^{a, b}$ \\ aLaboratory of Cardiovascular Immunology, Institute of Cardiology, Union Hospital, Tongji Medical \\ College, Huazhong University of Science and Technology, Wuhan, China, 'bInstitute of Cardiology, \\ Li-Yuan Hospital, Tongji Medical College of Huazhong University of Science and Technology, Wuhan, \\ 'Department of Cardiology, the First Affiliated Hospital of Zhengzhou University, Zhengzhou, China
}

\section{Key Words}

Acute coronary syndrome $\cdot$ Inflammation $•$ Atherosclerosis $\bullet$ Myeloid-derived suppressor cells

\begin{abstract}
Aim: The aim of this study was to explore whether the circulating frequency and function of myeloid-derived suppressor cells (MDSCs) are altered in patients with acute coronary syndrome (ACS). Methods: The frequency of MDSCs in peripheral blood was determined by flow cytometry, and mRNA expression in purified MDSCs was analyzed by real-time reverse transcription polymerase chain reaction (RT-PCR). The suppressive function of MDSCs isolated from different groups was also determined. The plasma levels of certain cytokines were determined using Bio-Plex Pro ${ }^{\mathrm{TM}}$ Human Cytokine Assays. Results: The frequency of circulating CD14 ${ }^{+} \mathrm{HLA}-\mathrm{DR} \mathrm{R}^{-1 / 0 w}$ MDSCs; arginase-1 (Arg-1) expression; and plasma levels of interleukin (IL)$1 \beta$, IL-6, tumor necrosis factor (TNF)- $\alpha$, and IL-33 were markedly increased in ACS patients compared to stable angina (SA) or control patients. Furthermore, MDSCs from ACS patients were more potent suppressors of T-cell proliferation and IFN- $\gamma$ production than those from the SA or control groups at ratios of 1:4 and 1:2; this effect was partially mediated by Arg-1. In addition, the frequency of MDSCs was positively correlated with plasma levels of IL-6, IL-33, and TNF- $\alpha$. Conclusions: We observed an increased frequency and suppressive function of MDSCs in ACS patients, a result that may provide insights into the mechanisms involved in ACS.

Y.-G. Wang and $\cdot \mathrm{X}$. Xiong contributed equally to this work.

Long-Xian Cheng,

and Wen-Cai Zhang,

KARGER 125
Lab Cardiovasc Immunol, Institute of Cardiol, Union Hospital, Tongji Medical College of Huazhong University of Science and Technology, Jie-Fang Avenue 1277\#, Wuhan, 430022 (China) and Dept of Cardiol, the First Affiliated Hospital of Zhengzhou University, Zhengzhou ( China) Tel. +8613707129705, E-Mail chenglongxian@sina.com or E-Mail zwc.8425@163.com 


\section{Introduction}

Atherosclerosis is a slowly progressing multifactorial disease in which the immune response may play a pivotal role [1]. Accumulating evidence confirms the involvement of innate and acquired immunity mediators in all stages of atherosclerosis as well as during plaque destabilization, which leads to the onset of acute coronary syndrome (ACS) [1-3]. Pathologically, atherosclerosis is characterized by chronic inflammation of the arterial wall, which activates the immune response and the release of leukocytes (e.g., monocytes, neutrophils, and lymphocytes) into predisposed regions of the intima. This initial response also promotes lipid deposition, resulting in early atherosclerotic plaques and lesion formation. Immune activation is considered the most significant feature in determining atherosclerotic plaque vulnerability. Specifically, the presence of activated inflammatory cells in plaque may increase vulnerability to and induce the occurrence of acute cardiovascular events, including ACS, through the release of matrix metalloproteinase, cytokines, and other mediators of inflammation [4-9]. Although substantial advances in this field have enhanced our understanding of atherosclerosis pathogenesis, the underlying molecular mechanisms have yet to be fully elucidated.

Myeloid-derived suppressor cells (MDSCs), which were first described in cancer patients in the late 1970s [10], are a phenotypically diverse population of bone marrowderived myeloid progenitor cells and immature myeloid cells with defects in differentiation [10-13]. Furthermore, MDSCs are the main cell type produced to negatively regulate the immune response [11] and function under a variety of pathological conditions [14-16]. The inhibitory properties of MDSCs are thought to be mediated by the depletion of L-arginine by arginase-1 (Arg-1) and inducible nitric oxidase (iNOS) [16]; cysteine sequestration [17]; reactive oxygen species (ROS) production [18]; interleukin-10 (IL-10) [19, 20]; and transforming growth factor-beta (TGF- $\beta 1$ ) [21] release and regulatory T-cell (Treg) induction [21]. Mouse MDSCs are positive for granulocyte (Gr1) and macrophage Mac-1 (CD11b) markers (otherwise known as $\mathrm{Gr} 1^{+} \mathrm{CD} 11 \mathrm{~b}^{+}$cells) $[22,23]$, but no uniform surface markers have been identified for human MDSCs. The two main subpopulations of human MDSCs are monocytic MDSCs (CD14 ${ }^{+}$LLA-DR ${ }^{-/ l o w}$ ) and granulocytic MDSCs (Lin-CD15 ${ }^{+}$CD $11 \mathrm{~b}^{+} \mathrm{CD}^{-} 3^{+}$) [23-26]. CD14+HLA-DR-/low cells in the peripheral blood of patients with hepatocellular carcinoma [21], melanoma [27], ovarian carcinoma [28], and inflammatory bowel disease [29] exhibit multiple characteristics of MDSCs.

Although the role of MDSCs in cancer has been intensively explored, additional work also implicates MDSCs in the pathogenesis of chronic inflammatory and autoimmune diseases, including inflammatory bowel disease [29], viral infection-related diseases [13], rheumatoid arthritis [30], and pulmonary hypertension [31]. However, little is known about the role of MDSCs in patients with ACS. In the present study, the population of MDSCs in the peripheral blood of ACS patients was characterized by flow cytometry. Furthermore, the suppressive nature of these MDSCs was also investigated in a co-culture model.

\section{Materials and Methods}

\section{Patients}

This investigation conforms to the principles of the Declaration of Helsinki. The study was approved by the ethics committee of Tongji Medical College of Huazhong University of Science and Technology, and informed consent was obtained from all subjects prior to this study. In this investigation, 169 (119 men and 50 women, $51.8 \pm 0.7$ years of age) patients at Union Hospital, Tongji Medical College of Huazhong University of Science and Technology, were enrolled and assigned to three groups. Patients were placed in the ACS group ( $\mathrm{n}=73,51$ men and 22 women, $53.8 \pm 1.0$ years of age) if they presented chest pain at rest accompanied by ischemic electrocardiographic changes, including ST-segment changes and T-wave inversions, or a significant increase in creatine kinase MB and troponin I levels. Patients were recruited to the stable angina (SA) group ( $\mathrm{n}=40,28$ men and 12 women, $51.6 \pm 1.6$ years of age) if they presented typical 
Wang et al.: Expansion of MDSCs in ACS Patients

exertional chest discomfort with down-sloping or horizontal ST-segment depression N1 $\mathrm{mm}$ in the exercise test. The control group ( $n=56,40$ men and 16 women, $49.2 \pm 1.4$ years of age) was composed of patients who had normal coronary artery arteries on angiography and no history of coronary heart disease. The baseline characteristics of the enrolled participants in all groups are shown in Table 1. Eligible patients were excluded if they had been treated with anti-inflammatory drugs or if they had a medical history of collagen disease, thromboembolism, disseminated intravascular coagulation, advanced liver disease, renal failure, malignant disease, or other inflammatory diseases.

\section{Blood Sample Preparation and Isolation of Peripheral Blood Mononuclear Cells (PBMCs)}

While in a fasting state on the morning of the admission day, blood samples were obtained via a 21-gauge needle for spotless antecubital venipuncture and collected into tubes containing $0.2 \mathrm{ml}$ of sodium heparin. The samples were obtained while the subjects were in a recumbent position. The blood samples were centrifuged at $300 \times g$ for $7 \mathrm{~min}$, and the plasma was then stored at $-20^{\circ} \mathrm{C}$. PBMCs in the blood were isolated by Ficoll-Hypaque (Sigma, USA) density gradient centrifugation and washed twice before flow cytometric analysis or magnetic cell sorting.

\section{Flow cytometric analysis}

PBMCs were harvested and stained with the following antibodies using the manufacturer's protocols: FITC-conjugated anti-human CD14 (clone: 61D3, eBioscience), PE-conjugated anti-human HLA-DR (clone: L243, eBioscience), FITC-conjugated anti-human Lin (CD3-clone: UCHT1, CD14-clone: HCD14, CD19-clone: HIB19, CD20-clone: 2H7, CD56-clone: HCD56, Biolegend), PE-conjugated anti-human CD11b (clone: M1/70, Biolegend), APC-conjugated anti-human CD33 (clone: WM53, BD Biosciences), and PE-Cy5-conjugated antihuman CD15 (clone: SSEA-1, Biolegend). The corresponding isotype antibodies were also used to enable correct compensation and to confirm antibody specificity. Then, the cells were washed with phosphatebuffered saline (PBS) and detected by flow cytometry with a FACS Calibur (BD Biosciences, USA) cell sorter. The results were analyzed using FlowJo7.6.1 (Treestar Inc., USA). Lymphocyte and monocyte counts were determined for all patients using an automated hematology analyzer (SYSMEX, XE-5000), and the estimated absolute number of MDSCs was calculated as follows: [total lymphocyte + monocyte count (cells/ $\mu \mathrm{l})] \times$ percentage CD14+xpercentage MDSCs/10000 [32-35].

\section{Isolation of MDSCs and T-cells}

CD14 ${ }^{+} \mathrm{HLA}^{-D R^{-/ l o w}}$ MDSCs were isolated from PBMCs as previously described [27] using CD14 and HLA-DR microbeads (Milenyi Biotec, Germany). Briefly, HLA-DR ${ }^{+}$cells were first removed by negative selection using an LD column, followed by further separation of the CD14 ${ }^{+} \mathrm{HLA}^{-D R^{-/ 10 w}}$ cells using anti-CD14 microbeads. The purity of the CD14 ${ }^{+} \mathrm{HLA}-\mathrm{DR}{ }^{-/ 10 w}$ cell population was $>80 \%$ as assessed by FACS. These MDSCs were then used for real-time polymerase chain reaction (RT-PCR) or functional assays as described below. In addition, autologous T-cells were isolated using CD3 microbeads (Milenyi Biotec, Germany) according to the manufacturer's instructions.

\section{Proliferation and Cytokine Secretion Assays}

Quantitative functional analysis of the MDSCs was performed by co-culturing sorted CD14+HLA-DR-/low MDSCs with autologous $\mathrm{CD}^{+}{ }^{+}$T-cells stimulated with anti-CD3/28 antibodies $(5 \mu \mathrm{g} / \mathrm{ml}$ ) (eBioscience, USA) at different suppressor-to-responder cell ratios $(0: 0,1: 8,1: 4$, and 1:2). The cells were grown in complete RPMI- 1640 medium at $37^{\circ} \mathrm{C}$ and $5 \% \mathrm{CO}_{2}$ in U-bottom 96 -well plates for $72 \mathrm{~h}$. In some experiments, the Arg-1 inhibitor $\mathrm{N}^{\omega}$-hydroxy-nor-L-arginine diacetate salt (nor-NOHA, Calbiochem, $200 \mu \mathrm{mol} / \mathrm{l}$ ), the iNOS inhibitor $N^{G}$-methyl-L-arginine acetate salt (L-NMMA, Sigma-Aldrich, $200 \mu \mathrm{mol} / \mathrm{l}$ ), neutralizing anti-TGF- $\beta$ antibodies (R\&D Biosystems, $10 \mu \mathrm{g} / \mathrm{ml}$ ) or anti-IL-10 antibodies (R\&D Biosystems, $10 \mu \mathrm{g} / \mathrm{ml}$ ) were also added. Approximately $16 \mathrm{~h}$ before harvesting the cells, $1 \mu \mathrm{Ci}$ of $\left[{ }^{3} \mathrm{H}\right]$-thymidine (Perkin Elmer; USA) was added to each well, and the incorporation of $\left[{ }^{3} \mathrm{H}\right]$-thymidine [36-38] was detected using a scintillation counter. Moreover, the concentration of interferon-gamma (IFN- $\gamma$ ) in the culture supernatant was detected using an enzyme-linked immunosorbent assay (ELISA) according to the manufacturer's instructions. The minimum detectable concentration of IFN- $\gamma$ (Neobioscience, China) was $8 \mathrm{pg} / \mathrm{ml}$, and all measurements were obtained twice.

\section{KARGER}


Table 1. Clinical data for the ACS, SA, and control patients enrolled in this study. The values are presented as the mean \pm SEM or number $(\%)$. ACS: acute coronary syndrome; SA: stable angina; ACEI: angiotensin converting enzyme inhibitor; ARB: angiotensin receptor blocker

\begin{tabular}{lllll}
\hline Baseline Characteristic & $\begin{array}{l}\text { ACS } \\
(\mathrm{n}=73)\end{array}$ & $\begin{array}{l}\text { SA } \\
(\mathrm{n}=40)\end{array}$ & $\begin{array}{l}\text { Control } \\
(\mathrm{n}=56)\end{array}$ & P-value \\
\hline Sex (female/male) & $22 / 51$ & $12 / 28$ & $16 / 40$ & 0.979 \\
Age (years) & $53.8 \pm 1.0$ & $51.6 \pm 1.6$ & $49.2 \pm 1.4$ & 0.130 \\
& & & & \\
Risk factors, n (\%) & & & & \\
Hypertension & $34(47)$ & $17(43)$ & $15(27)$ & 0.065 \\
Diabetes mellitus & $19(26)$ & $8(20)$ & $8(14)$ & 0.262 \\
Hyperlipidemia & $27(37)$ & $13(33)$ & $7(13)$ & 0.007 \\
Current smoking & $15(21)$ & $9(23)$ & $10(18)$ & 0.849 \\
Obesity & $20(27)$ & $11(28)$ & $10(18)$ & 0.393 \\
& & & & \\
Medications, n (\%) & $35(48)$ & $18(45)$ & $11(20)$ & 0.003 \\
Aspirin & $30(41)$ & $20(50)$ & $13(23)$ & 0.019 \\
ACEI/ARBs & $32(44)$ & $18(45)$ & $6(11)$ & 0.000 \\
Statins & $27(37)$ & $17(43)$ & $7(13)$ & 0.002 \\
Beta-blockers & $16(22)$ & $9(23)$ & $9(16)$ & 0.651 \\
Calcium blockers & $14(19)$ & $7(18)$ & $1(2)$ & 0.009 \\
Nitrates & $13(18)$ & $7(18)$ & $4(7)$ & 0.180 \\
Hypoglycemic agent & & & & \\
\hline
\end{tabular}

RT-PCR

Total RNA was extracted from fresh bead-sorted MDSCs using Trizol reagent (Takara, Japan) according to the manufacturer's instructions. cDNA was produced by reverse transcription using a Reverse Transcriptase kit (Takara, Japan). Gene expression levels were detected using SYBR Green Nucleic Acid Gel Stains (Takara, Japan) using the $-2^{\Delta \Delta \mathrm{CT}}$ method, and samples were analyzed with an ABI Prism 7900 Sequence Detection System (Applied Biosystems, USA). The following primer sequences were used: Arg-1 (F: 5'-GGCTGGTCTGCTTGAGAAAC-3', R: 5'-ATTGCCAAACTGTGGTC TCC-3'), iNOS (F: 5'-CTTTCCAAGACACACTTCACCA-3', R: 5'-TA TCTCCTTTGTTACCGCTTCC-3'), TGF- $\beta 1$ (F: 5'-TGAGGGCTTTCG CCTTAGC-3', R: 5'-CGGTAGTGAACCCGTTGATGT-3'), IL-10 (F: 5'-GGCCAGGGCACCCAGTCT-3', R: 5'-TCGAAGCATGTTAGGCA GGTT-3') and GAPDH (F: 5'-CCACATCGCTCAGACACCAT-3', R 5'-GGCAACAATATCCACTTTACCAGAGT-3'). Samples were amplified in duplicate for 40 cycles, and gene expression levels were normalized to the levels of the housekeeping gene GAPDH.

\section{Multiplex Cytokine Assays}

The plasma levels of IL-6, IL-10, IL-33, IL-1 $\beta$, and tumor necrosis factor (TNF)- $\alpha$ were measured using a unique blend of magnetic bead-based multiplex immunoassays (Bio-Plex Pro ${ }^{\text {TM }}$ Human Cytokine Assays; Bio-Rad Laboratories; USA), as previously described [39, 40]. Cytokine concentrations were determined using the Bio-Plex 200 System $^{\text {TM }}$ (Bio-Rad Ltd.; USA) and are expressed as pg/ml. All samples were measured twice.

\section{Statistical Analysis}

The data are presented as the mean \pm standard error of the mean (SEM) or as a percentage in the text and figures. One-way ANOVA tests and Pearson chi-square tests were used to detect significant differences between the three groups. Spearman's correlation analysis was used to determine any correlation between the variables. In all cases, a p-value less than 0.05 was considered statistically significant. SPSS statistics 17.0 software was used for the statistical analyses.

\section{Results}

\section{Baseline Patient Characteristics}

The clinical data of the enrolled participants in all groups are listed in Table 1 . There were no significant differences with respect to age, gender, hypertension, diabetes mellitus status, smoking status, obesity, or the use of calcium blockers or anti-diabetic drugs. However, the incidence rate of hyperlipidemia and the utilization of aspirin, angiotensin-converting enzyme inhibitor (ACEI) or angiotensin receptor blockers (ARBs), statins, $\beta$-blockers and nitrates were markedly higher in patients with ACS and SA than in the control group. 
Fig. 1. The frequency and counts of circulating CD14+HLA-DR-/low MDSCs are significantly increased in patients with ACS. (A) CD14+ monocytes were gated by flow cytometry. (B) Representative images of the frequencies of

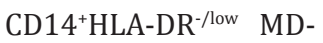
SCs from a single patient in each group. (C) The percentages of $\mathrm{CD}^{+} 4^{+}$monocytes among PBMCs for each group. (D) The percentages of $\mathrm{CD} 14^{+} \mathrm{H}-$ LA-DR-/low MDSCs within the CD14+ monocytes for each group. (E) The estimated absolute number of CD14+HLA-DR-/low cells in the patients in each group.

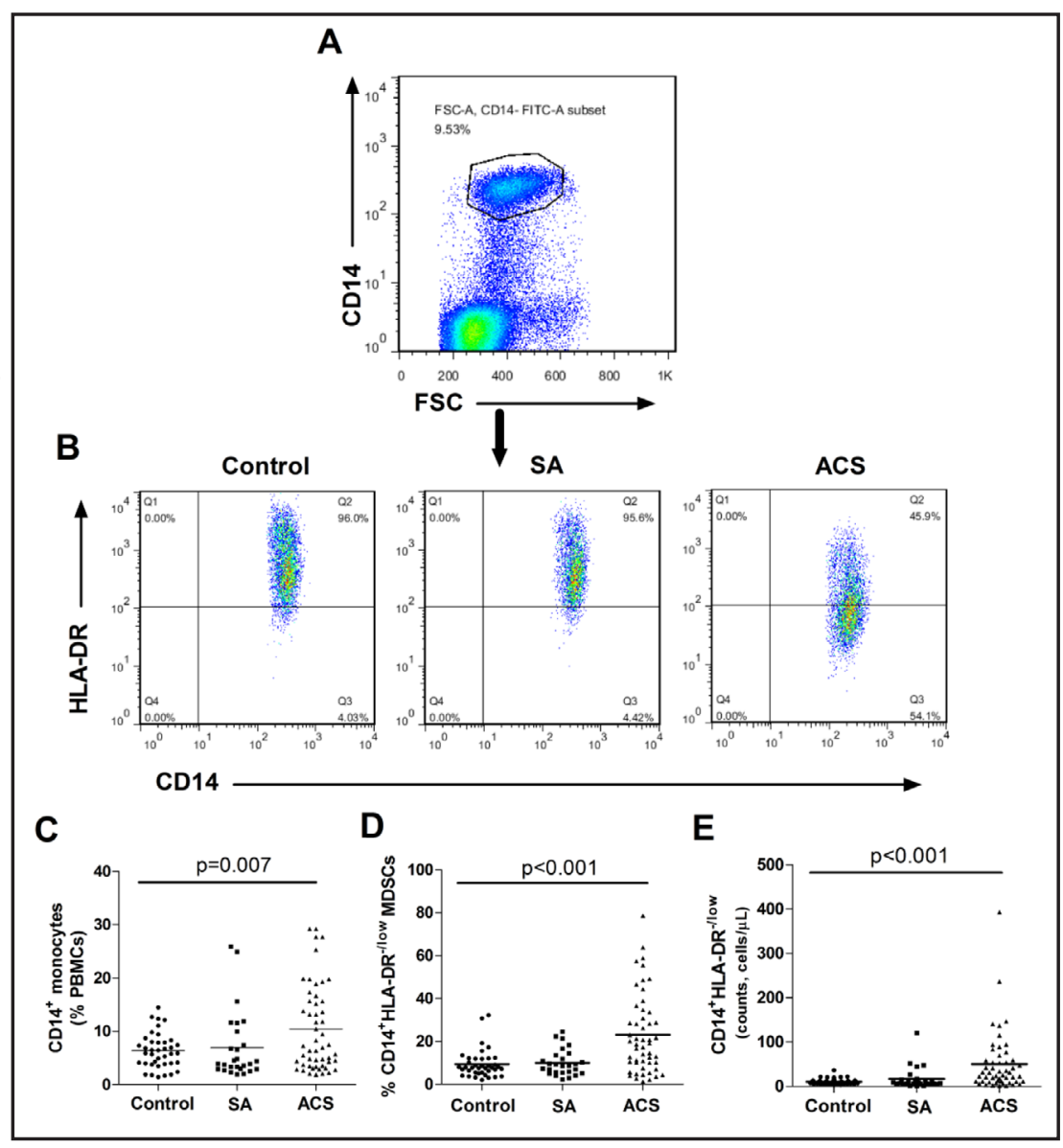

CD14+HLA-DR-/low MDSC Frequency in the Peripheral Blood of ACS Patients

To determine whether MDSCs play a role in ACS pathology, we compared the MDSC frequency in the peripheral blood of patients in the ACS, SA, and control groups. The frequency of $\mathrm{CD}_{14}{ }^{+}$monocytes among PBMCs was higher in ACS patients $110.39 \% \pm$ $1.12 \%, p=0.007)$ than in patients in the SA $(6.96 \% \pm 1.24 \%)$ and control $(6.33 \% \pm 0.53 \%)$ groups (Fig. 1C). Furthermore, the percentage of CD14+HLA-DR-/low cells was significantly increased in $\mathrm{CD} 14^{+}$monocytes of ACS patients $(23.1 \% \pm 2.6 \%, \mathrm{p}<0.001)$ compared to those of patients in the SA $(10.1 \% \pm 1.2 \%)$ and control $(9.4 \% \pm 1.0 \%)$ groups (Fig. 1D). In addition, a comparative analysis using estimated absolute numbers (calculated based on the lymphocyte and monocyte counts in PBMCs and in the case of whole blood) revealed that the absolute number of CD14+HLA-DR-/low cells was significantly increased in the peripheral blood of ACS patients (50.08 cells $/ \mu \mathrm{l} \pm 9.32$ cells $/ \mu \mathrm{l}, \mathrm{p}<0.001)$ compared to patients in the SA $(16.92$ cells $/ \mu \mathrm{l} \pm 4.78$ cells $/ \mu \mathrm{l})$ and control $(10.63$ cells $/ \mu \mathrm{l} \pm 1.08$ cells $/ \mu \mathrm{l})$ groups (Fig. $1 \mathrm{E})$. However, no difference in the percentages of Lin ${ }^{-} \mathrm{CD} 15^{+} \mathrm{CD} 11 \mathrm{~b}^{+} \mathrm{CD} 33^{+}$cells was detected among patients in the ACS, SA and control groups (Fig. 2A and B).

The Suppressive Function of MDSCs from ACS Patients

MDSCs may suppress antigen-specific and antigen-non-specific T-cell responses. In this study, proliferation and cytokine secretion assays were conducted using a co-culture model to determine if CD14 ${ }^{+} \mathrm{HLA}^{-D R^{-/ l o w}}$ MDSCs isolated from patients can inhibit T-cell proliferation and cytokine secretion. The regulatory action of the cells from the various groups was also compared. First, flow cytometry was performed to detect the purity of the MDSCs after cell sorting (Fig. 3A and B). As shown in Figures 4A, B and C, the CD14+HLA$\mathrm{DR}^{-/ \text {low }}$ cells suppressed T-cell proliferation and IFN- $\gamma$ production in a dose-dependent manner. Furthermore, two of the suppressor-to-responder cell ratios (1:4 and 1:2) inhibited 
Fig. 2. There were no significant differences in the frequency of circulating granulocytic L i n C D $15{ }^{+}$C D $11 \mathrm{~b}^{+} \mathrm{CD} 33^{+} \quad \mathrm{MD}-$ SCs among the patients from the three groups. (A) Representative dot plots of Lin $^{-} \mathrm{CD} 15^{+} \mathrm{CD}$ $11 b^{+} \mathrm{CD}^{+} \quad \mathrm{MD}-$ SCs. (B) The percentages of L i n C D $15^{+}$C D $11 b^{+}{ }^{+} D 33^{+}$MDSCs among PBMCs from the patients in the ACS $(n=21)$, SA $(n=13)$ and control $(n=17)$ groups.

Fig. 3. Purity of the $\mathrm{CD} 14^{+} \mathrm{H}-$ LA-DR-/low MDSCs isolated using magnetic selection. (A) Dot plot showing the purity of the MDSCs before isolation. (B) Dot plot showing the purity of the MDSCs after isolation.
A
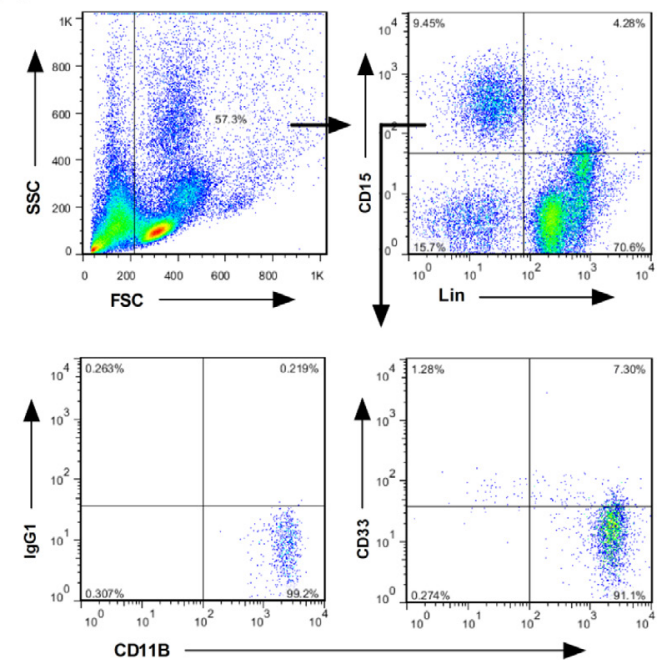

B

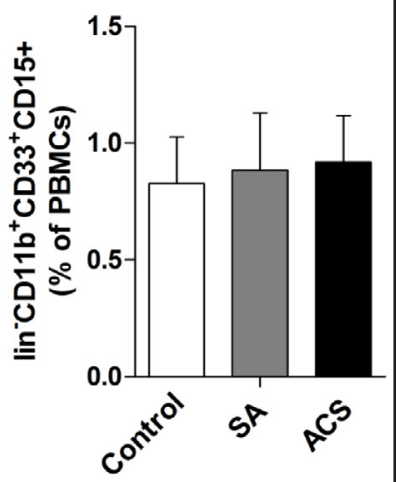

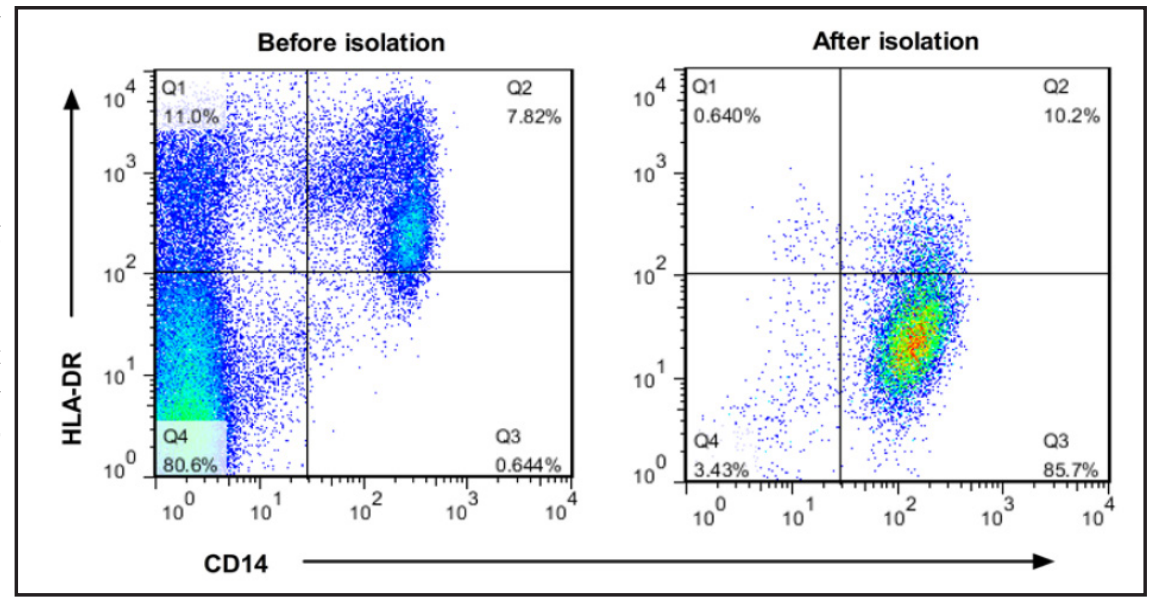

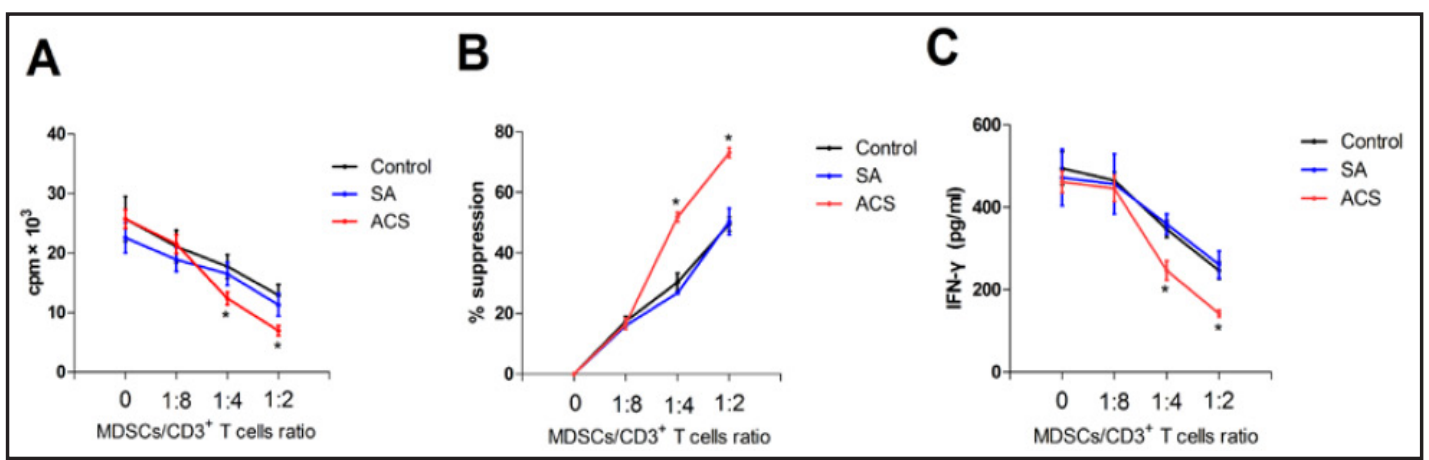

Fig. 4. MDSCs from ACS patients exhibit increased suppressive function. CD14 ${ }^{+} \mathrm{HLA}^{-\mathrm{DR}^{-/ \text {low }}} \mathrm{MDSCs}^{-}$and CD3 ${ }^{+}$ T-cells from ACS patients $(n=6)$, SA patients $(n=6)$ and controls $(n=6)$ were purified by magnetic cell sorting. (A) $\left[{ }^{3} \mathrm{H}\right]$-Thymidine uptake was used to evaluate the effector cell proliferative indexes. (B) MDSC inhibition of the effector cells expressed as a percentage. (C) Increased suppressive function of the MDSCs from ACS patients was suggested by the IFN- $\gamma$ production level. ${ }^{*} \mathrm{p}<0.05$ compared to the SA or control groups.

T-cell proliferation and IFN- $\gamma$ production more effectively for cells from ACS patients than those from the SA and control groups (Fig. 4B and C). 


\begin{tabular}{|c|c|c|}
\hline Cellular Physiology & Cell Physiol Biochem 2015;35:292-304 & \\
\hline and Biochemistry & $\begin{array}{l}\text { DOI: 10.1159/000369696 } \\
\text { Publisned onine: January 10, } 2015\end{array}$ & $\begin{array}{l}\text { O } 2015 \text { S. Karger AG, Basel } \\
\text { www.karger.com/cpb }\end{array}$ \\
\hline
\end{tabular}

Fig. 5. ARG-1 mRNA expression was increased in MDSCs purified from ACS patients. RT-PCR was used to detect the mRNA expression of Arg1 (A), iNOS (B), TGF- $\beta 1(\mathrm{C})$, and IL-10 (D) in purified MDSCs from patients in the $\operatorname{ACS}(n=12), \operatorname{SA}(n=10)$, and control $(\mathrm{n}=12)$ groups.
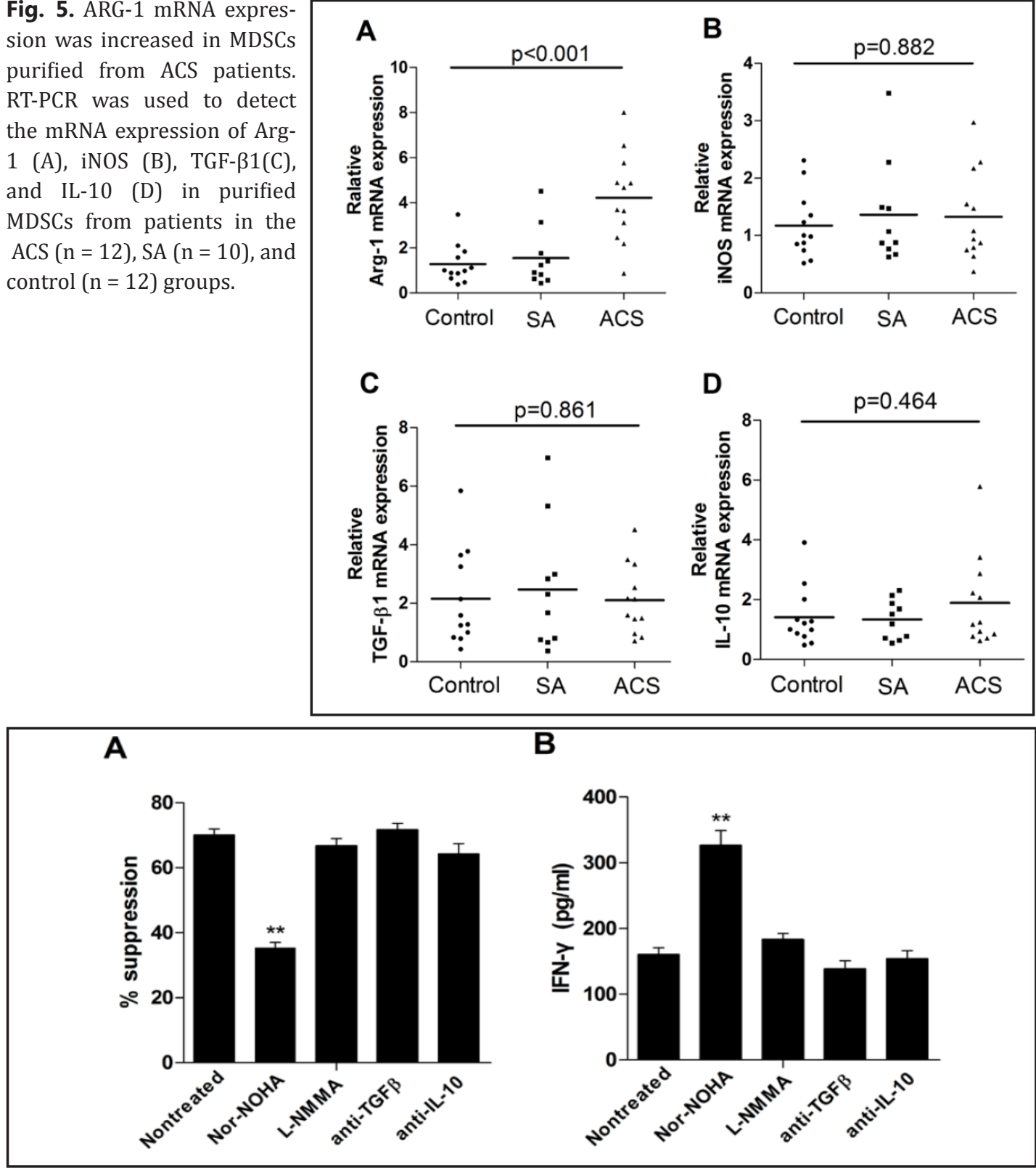

Fig. 6. The inhibition of autologous T-cell proliferation and IFN- $\gamma$ production by CD14+HLA-DR ${ }^{-/ \text {low }}$ MDSCs is partially Arg-1 dependent. The effects of variable chemical inhibitors and blocking antibodies on the CD14 ${ }^{+} \mathrm{HLA}_{-\mathrm{DR}}{ }^{- \text {low }}$ MDSC-induced suppression of autologous $\mathrm{CD}^{+}{ }^{+}$-cell proliferation (A) and IFN- $\gamma$ production (B). nor-NOHA, $\mathrm{N}^{\omega}$-Hydroxy-nor-L-arginine diacetate salt; L-NMMA, $\mathrm{N}^{\mathrm{G}}$-Methyl-L-arginine acetate salt; anti-TGF- $\beta$, neutralizing anti-TGF- $\beta$ antibodies; anti-IL-10, neutralizing anti-IL-10 antibodies. ${ }^{*} \mathrm{p}<0.01$ compared to the non-treated groups.

\section{Arg-1 mRNA Expression is Increased in MDSCs Purified from ACS Patients}

MDSCs can suppress immune responses under pathological conditions via diverse mechanisms, including increased arginase activity, nitric oxide (NO) levels, and the release of IL-10 and TGF- $\beta 1$. Here, we analyzed the mRNA expression of Arg- 1 , iNOS, TGF- $\beta 1$, and IL10 in the sorted CD $14^{+} \mathrm{HLA}^{-D R^{-/ l o w}}$ cells by RT-PCR. Arg- 1 mRNA expression was significantly increased in the sorted MDSCs from the ACS patients compared to MDSCs from the SA and control groups $(p<0.01)$ (Fig. 5A). No significant differences in iNOS, TGF- $\beta 1$, or IL-10 expression were observed among the three groups ( $p>0.05$ ) (Fig. 5B, C and D). 


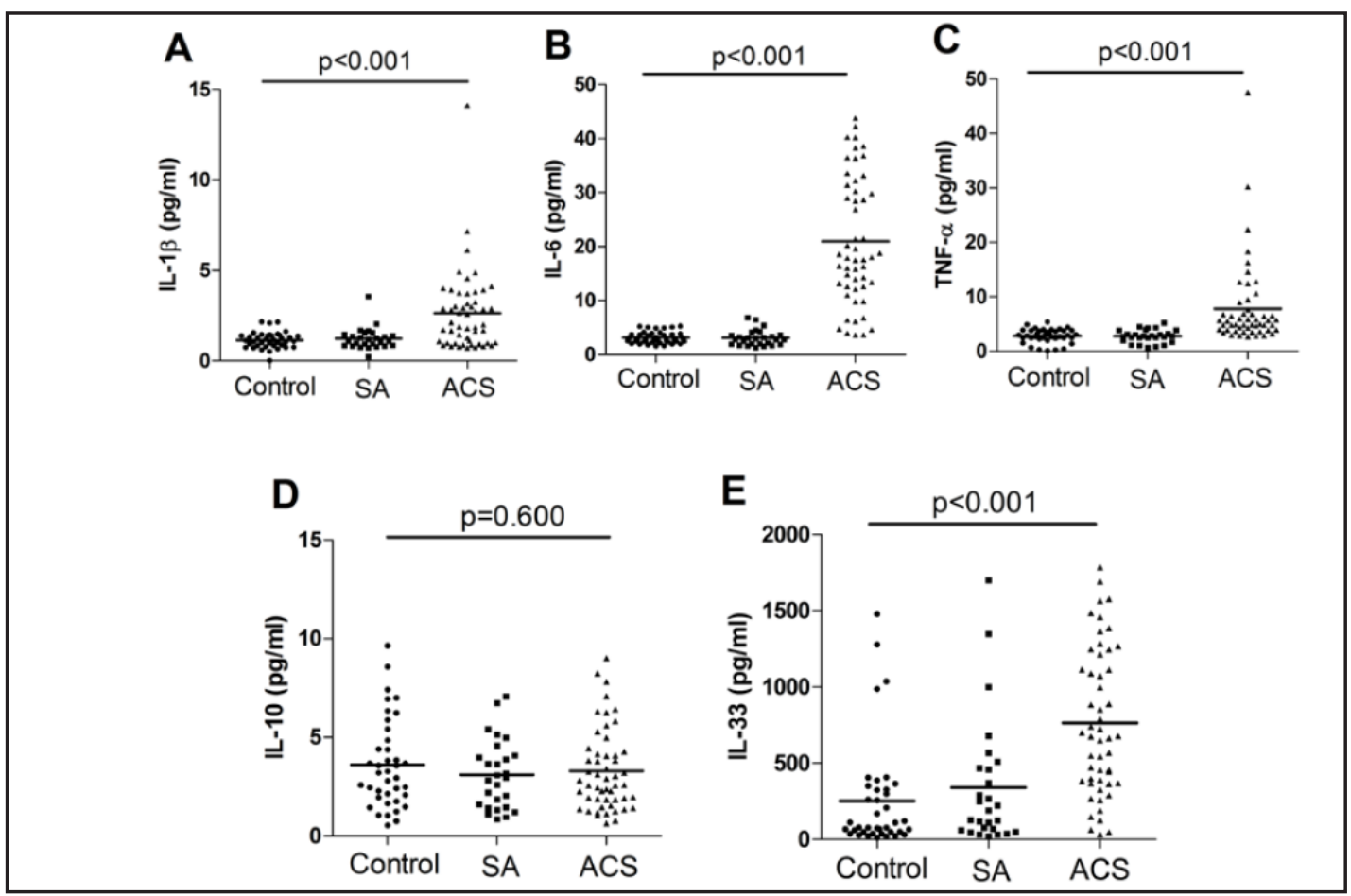

Fig. 7. Increased levels of plasma cytokines in ACS patients. The plasma concentrations of IL-1 $\beta$ (A), IL-6 (B), TNF- $\alpha(C)$, IL-10 (D), and IL-33 (E) were determined using the Bio-Plex system.
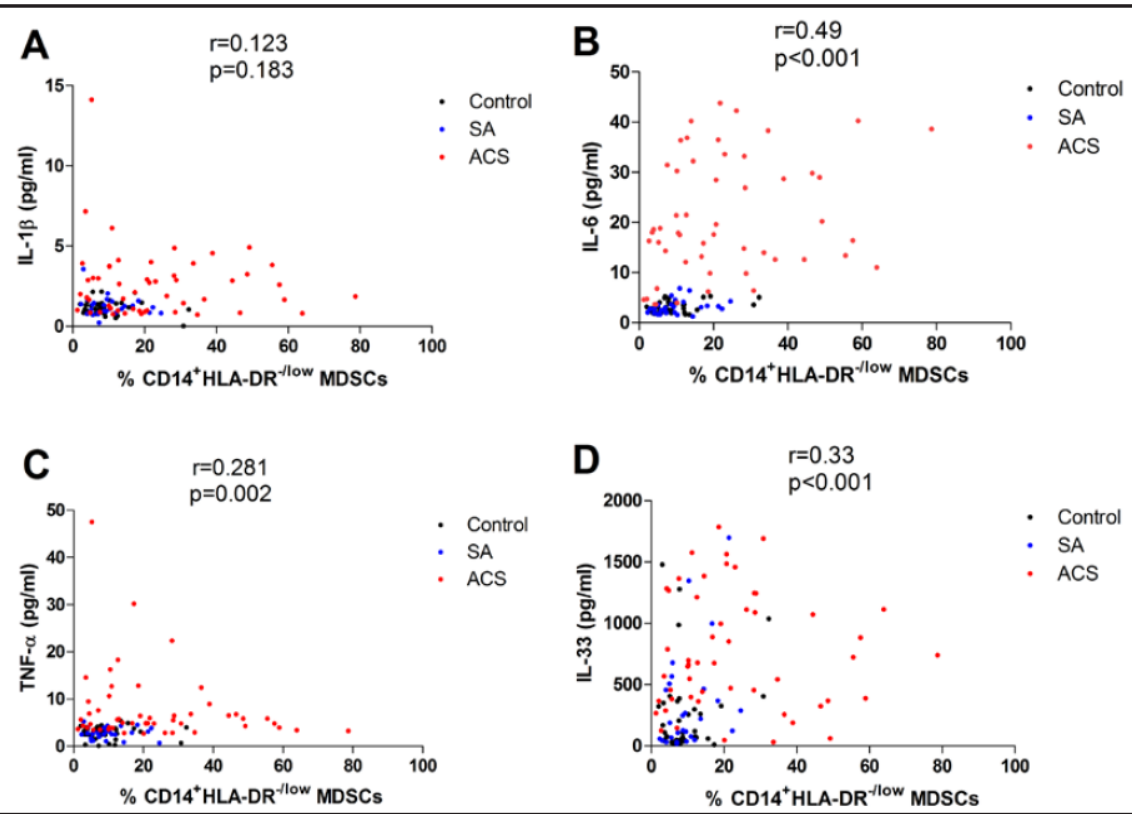

Fig. 8. Spearman correlation analysis of the relationships between the frequency of CD14+HLA-DR-/low MDSCs and related cytokines in patients in the ACS, SA, and control groups. (A) No significant association was observed between MDSC frequency and the plasma level of IL-1 $\beta(r=0.123, p=0.183)$. The frequency of MDSCs was positively correlated with the plasma levels of IL-6 ( $r=0.49, p<0.001)(B)$, TNF- $\alpha(r=0.281$, $\mathrm{p}=0.002)(\mathrm{C})$, and IL-33 ( $\mathrm{r}=0.33, \mathrm{p}<0.001)(\mathrm{D})$.

MDSCs from ACS patients Suppress T-cell Responses Primarily via Arg-1

To further delineate the possible mechanisms by which CD14+HLA-DR-/low MDSCs from ACS patients inhibit T-cell function, we evaluated the suppressive function of CD14 HLA- 
$\mathrm{DR}^{-/ \text {low }}$ MDSCs following the addition of different chemical inhibitors or blocking antibodies. Consistent with the RT-PCR results, the suppression of T-cell proliferation and IFN- $\gamma$ production by MDSCs was partially recovered after administration of the Arg-1 inhibitor nor-NOHA. No effect was observed for the iNOS inhibitor L-NMMA, neutralizing anti-TGF- $\beta$ antibodies or anti-IL-10 antibodies (Fig. 6).

The Correlation of CD14+HLA-DR-/low Cell Frequency with Inflammatory Cytokines

Recent work has demonstrated that cytokines may be key players in the systemic immune response during atherosclerosis and can enhance the accumulation, differentiation arrest, and activation of immature myeloid cells. Thus, to determine the relationship between these cytokines and CD14 ${ }^{+} \mathrm{HLA}^{-\mathrm{DR}^{-/ / 10 w}}$ cells, the plasma levels of several important cytokines were examined. The concentrations of IL-1 $\beta$, IL- 6 , TNF- $\alpha$, and IL-33 were significantly higher in patients with ACS $(2.64 \pm 0.31 \mathrm{pg} / \mathrm{ml}, 20.97 \pm 1.62 \mathrm{pg} / \mathrm{ml}, 7.82 \pm 1.07 \mathrm{pg} / \mathrm{ml}$, and 763.85 $\pm 66.47 \mathrm{pg} / \mathrm{ml}$, respectively) than in patients in the SA $(1.23 \pm 0.12 \mathrm{pg} / \mathrm{ml}, 3.20 \pm 0.28 \mathrm{pg} /$ $\mathrm{ml}, 2.78 \pm 0.23 \mathrm{pg} / \mathrm{ml}$, and $341.11 \pm 80.47 \mathrm{pg} / \mathrm{ml}$, respectively) and control (1.15 $\pm 0.07 \mathrm{pg} /$ $\mathrm{ml}, 3.14 \pm 0.17 \mathrm{pg} / \mathrm{ml}, 2.83 \pm 0.21 \mathrm{pg} / \mathrm{ml}, 252.70 \pm 56.46 \mathrm{pg} / \mathrm{ml}$, respectively) groups (all $\mathrm{p}$ $<0.001$ ) (Fig. 7A, B, C and E). By contrast, the differences in the plasma levels of IL-10 were not statistically significant among the ACS $(3.61 \pm 0.36 \mathrm{pg} / \mathrm{ml})$, SA $(3.11 \pm 0.34 \mathrm{pg} / \mathrm{ml})$ and control (3.31 $\pm 0.28 \mathrm{pg} / \mathrm{ml})$ patients (Fig. 7D). We next performed a correlation analysis of MDSC frequency and plasma cytokine levels in all patients. The frequency of MDSCs was significantly correlated with the plasma levels of IL-6 ( $\mathrm{r}=0.49, \mathrm{p}<0.001)$ (Fig. 8B), TNF- $\alpha$ $(\mathrm{r}=0.281, \mathrm{p}=0.002$ ) (Fig. 8C), and IL-33 ( $\mathrm{r}=0.33, \mathrm{p}<0.001$ ) (Fig. 8D) in this cohort; no significant association was noted between MDSC frequency and IL-1 $\beta$ levels $(r=0.123, p=$ 0.183) (Fig. 8A).

\section{Discussion}

The treatment of cardiovascular disease (CVD), a severe global epidemic associated with high prevalence, incidence, and mortality, remains a major challenge for most countries. Inflammatory processes play crucial roles in the pathogenesis of atherosclerosis plaque development, including plaque destabilization and the onset of ACS [4-7]. However, the specific pathological mechanism is unclear, and additional details are needed to understand the full effects of these processes [41].

MDSCs, which are characterized by their myeloid origin, immature state, and potent ability to suppress T-cell responses, have been studied intensively in cancer research and are increasing recognized for their role in inflammation-mediated diseases [13, 29, 30]. Atherosclerosis involves cross-talk between the adaptive and innate immunity pathways $[2,3]$. By evoking elements of the host defense system, atherosclerosis involves many of the same processes and factors that function during other chronic inflammatory diseases. MDSCs accumulate in response to chronic inflammation and have well-characterized immunomodulatory activities, leading us to hypothesize that MDSCs may be altered in patients with atherosclerosis, particularly ACS, which is closely associated with abnormal immune system activation.

In this study, we observed a significant increase in the frequency of human CD14+HLA$\mathrm{DR}^{-/ / \text {low }}$ MDSCs in the peripheral blood of patients with ACS compared with those in the SA and control groups. The MDSC frequency was only slightly higher in SA patients compared with patients in the control group; however, this difference was not statistically significant. A number of studies support the view that the initiation of atherosclerosis is accompanied by inappropriate activation of the immune system in response to the accumulation and modification of lipoproteins in the arterial intima [1-3, 6]. Taken together, our observations indicate that in the context of ACS, a severe systemic inflammatory reaction, the release of important cytokines, and a modification of the local microenvironment may underlie the expansion of MDSCs. Similar to what Haile observed in IBD [29], we suspect that ACS 
increases the frequency of immunosuppressive MDSCs, thereby preventing the development of a more severe and possibly fatal inflammatory response.

To determine whether ACS-derived MDSCs could suppress T-cell function, T-cell proliferation and IFN- $\gamma$ production were measured in the MDSC-T-cell co-culture system. Similar to results observed for hepatitis [13], we determined that purified MDSCs suppressed T-cell proliferation and IFN- $\gamma$ production in a dose-dependent manner. Furthermore, at ratios of 1:4 and 1:2, MDSCs from ACS patients inhibited T-cell proliferation and IFN- $\gamma$ production more efficiently than those from the SA and control groups. These results suggest that the MDSCs of ACS patients not only occur at a drastically increased frequency but also exhibit an upregulated suppressive effect on a per cell basis compared with MDSCs from SA and control patients. The metabolism and metabolic products of L-arginine are essential for suppressive MDSCs [11,13, 27]. Thus, to investigate the mechanism of MDSC-mediated T-cell suppression in ACS patients, we compared the mRNA expression levels of Arg-1, iNOS, TGF- $\beta 1$, and IL-10 in MDSCs isolated from patients in the three groups. We also tested the suppressive function of CD14+HLA-DR-/low MDSCs in the presence of different chemical inhibitors or blocking antibodies. Our observations revealed that active MDSCs in ACS patients expressed higher transcript levels of Arg- 1 but not iNOS, TGF- $\beta 1$, or IL-10. In addition, the Arg-1 inhibitor norNOHA nearly neutralized the suppressive function of MDSCs. A neutralizing effect was not observed for the iNOS inhibitor L-NMMA or neutralizing anti-TGF- $\beta$ or anti-IL-10 antibodies. These results suggest that Arg- 1 is one of the main suppressive mechanisms utilized during MDSC-mediated suppression of T-cell proliferation in ACS patients.

A substantial body of evidence suggests the involvement of the systemic immune response in the pathogenesis of atherosclerosis and a possible role for cytokines in the development, progression, and complications of this disease [42-44]. Cytokines are defined as lymphocyte-derived proteins that affect the growth or function of immune cells and that are secreted from a variety of cell sources. In this study, we measured the levels of numerous cytokines in plasma samples isolated from ACS, SA, and control patients. Our data suggest that plasma IL-1 $\beta$, IL-6, TNF- $\alpha$, and IL-33 levels are all elevated in ACS patients, further validating the conclusions above. Several studies have demonstrated that certain cytokines can promote the accumulation, differentiation arrest, and activation of immature myeloid cells $[18,45,46]$. Thus, we sought to examine the possible correlations between these cytokines and MDSC frequency in all patients. A higher frequency of circulating MDSCs was positively correlated with IL-6, TNF- $\alpha$, and IL-33 levels, indicating that these cytokines, which are likely responsible for plaque destabilization, may also contribute to the release of additional MDSCs from bone marrow.

The dramatic expansion of the CD14 ${ }^{+} \mathrm{HLA}^{-D R^{-/ / 0 w}}$ MDSC population in response to ACS is very similar to that previously described in patients with other inflammatory diseases [13, 29-31]. Although the direct mechanism of MDSC generation has not been fully elucidated, several lines of evidence offer clues as to how the high frequency of circulating MDSCs might occur in the context of ACS. First, MDSCs are a heterogeneous population of cells, and the local inflammatory microenvironment greatly affects their tissue recruitment, retention, and immunomodulatory capabilities [45]. ACS occurs as a consequence of coronary plaque erosion or rupture, and severe systemic inflammation is thought to play an important role in these coronary events. Therefore, the high frequency of circulating MDSCs may occur because systemic inflammation during coronary plaque erosion or rupture stimulates the bone marrow to release more MDSCs into the peripheral blood. Second, it has been reported that MDSCs can mediate Treg induction through various mechanisms [21, 47, 48]. However, downregulation of Treg cells occurs in ACS patients [8, 9]. This relationship between Treg cells and MDSCs suggests that multiple mechanisms and molecules are involved in the expansion of MDSCs in ACS. Notably, it has been reported that IL- 6 potently activates phosphorylated signal transducer and activator of transcription 3 (pSTAT3) and augments MDSC survival, thereby promoting MDSC expansion [49]. In addition, IL-33 stimulates the activation of macrophages that produce G-CSF, boosting the number and survival of MDSCs [50]. In this study, the plasma levels of IL- 6 and IL-33 were elevated in ACS patients, and the 
increased levels of these cytokines were positively correlated with MDSC frequency. These findings support the hypothesis that several cytokines, such as IL-6 and IL-33, may also be involved in the process of MDSC expansion in ACS patients.

This study is subject to several limitations. First, the study population was relatively small, and additional studies with more patients are necessary for a more in-depth comparison. Second, our in vitro results indicated a potential role of MDSCs in ACS patients. However, further studies using animal models of atherosclerosis are required to fully investigate the in vivo function of MDSCs and identify the precise effects and mechanisms of MDSC expansion in plaque progression and destabilization.

In summary, this is the first study to demonstrate an expansion of CD14+HLA-DR-/low MDSCs with immunosuppressive function in patients with ACS. The expansion of these cells into the peripheral blood may be induced by severe systemic inflammation to maintain immune homeostasis during the onset of ACS; however, additional studies are needed to elucidate the mechanistic link between MDSCs and the pathogenesis of ACS. Further elucidation of the role of MDSCs in patients with ACS will may provide additional treatment targets for the clinical management of atherosclerosis and ACS.

\section{Acknowledgments}

This work was supported by grants from the National Natural Science Foundation of China [No. 81370324 to LXC].

\section{Disclosure Statement}

The authors have no competing interests to declare.

\section{References}

1 Ross R: Atherosclerosis--an inflammatory disease. N Engl J Med 1999;340:115-126.

2 Hansson GK: Inflammation, atherosclerosis, and coronary artery disease. N Engl J Med 2005;352:16851695.

3 Hansson GK: Innate and adaptive immunity in the pathogenesis of atherosclerosis. Circ Res 2002;91:281291.

4 Edfeldt K, Swedenborg J, Hansson GK, Yan ZQ: Expression of toll-like receptors in human atherosclerotic lesions: A possible pathway for plaque activation. Circulation 2002;105:1158-1161.

5 Bjorkbacka H, Kunjathoor VV, Moore KJ, Koehn S, Ordija CM, Lee MA, Means T, Halmen K, Luster AD, Golenbock DT, Freeman MW: Reduced atherosclerosis in myd88-null mice links elevated serum cholesterol levels to activation of innate immunity signaling pathways. Nat Med 2004;10:416-421.

-6 Laurat E, Poirier B, Tupin E, Caligiuri G, Hansson GK, Bariety J, Nicoletti A: In vivo downregulation of t helper cell 1 immune responses reduces atherogenesis in apolipoprotein e-knockout mice. Circulation 2001;104:197-202.

7 Frostegard J, Ulfgren AK, Nyberg P, Hedin U, Swedenborg J, Andersson U, Hansson GK: Cytokine expression in advanced human atherosclerotic plaques: Dominance of pro-inflammatory (th1) and macrophagestimulating cytokines. Atherosclerosis 1999;145:33-43.

8 Cheng X, Yu X, Ding YJ, Fu QQ Xie JJ, Tang TT, Yao R, Chen Y, Liao YH: The th17/treg imbalance in patients with acute coronary syndrome. Clin Immunol 2008;127:89-97.

-9 Zhang WC, Wang J, Shu YW, Tang TT, Zhu ZF, Xia N, Nie SF, Liu J, Zhou SF, Li JJ, Xiao H, Yuan J, Liao MY, Cheng LX, Liao YH, Cheng X: Impaired thymic export and increased apoptosis account for regulatory t cell defects in patients with non-st segment elevation acute coronary syndrome. J Biol Chem 2012;287:34157-34166

10 Young MR, Newby M, Wepsic HT: Hematopoiesis and suppressor bone marrow cells in mice bearing large metastatic lewis lung carcinoma tumors. Cancer Res 1987;47:100-105. 
Wang et al.: Expansion of MDSCs in ACS Patients

11 Gabrilovich DI, Nagaraj S: Myeloid-derived suppressor cells as regulators of the immune system. Nat Rev Immunol 2009;9:162-174.

12 Greten TF, Manns MP, Korangy F: Myeloid derived suppressor cells in human diseases. Int Immunopharmacol 2011;11:802-807.

13 Cai W, Qin A, Guo P, Yan D, Hu F, Yang Q Xu M, Fu Y, Zhou J, Tang X: Clinical significance and functional studies of myeloid-derived suppressor cells in chronic hepatitis c patients. J Clin Immunol 2013;33:798808.

14 Marhaba R, Vitacolonna M, Hildebrand D, Baniyash M, Freyschmidt-Paul P, Zoller M: The importance of myeloid-derived suppressor cells in the regulation of autoimmune effector cells by a chronic contact eczema. J Immunol 2007;179:5071-5081.

-15 Sun HL, Zhou X, Xue YF, Wang K, Shen YF, Mao JJ, Guo HF, Miao ZN: Increased frequency and clinical significance of myeloid-derived suppressor cells in human colorectal carcinoma. World J Gastroenterol 2012;18:3303-3309.

16 Youn JI, Gabrilovich DI: The biology of myeloid-derived suppressor cells: The blessing and the curse of morphological and functional heterogeneity. Eur J Immunol 2010;40:2969-2975.

17 Srivastava MK, Sinha P, Clements VK, Rodriguez P, Ostrand-Rosenberg S: Myeloid-derived suppressor cells inhibit t-cell activation by depleting cystine and cysteine. Cancer Res 2010;70:68-77.

18 Corzo CA, Cotter MJ, Cheng P, Cheng F, Kusmartsev S, Sotomayor E, Padhya T, McCaffrey TV, McCaffrey JC, Gabrilovich DI: Mechanism regulating reactive oxygen species in tumor-induced myeloid-derived suppressor cells. J Immunol 2009;182:5693-5701.

19 Loercher AE, Nash MA, Kavanagh JJ, Platsoucas CD, Freedman RS: Identification of an il-10-producing hla-dr-negative monocyte subset in the malignant ascites of patients with ovarian carcinoma that inhibits cytokine protein expression and proliferation of autologous t cells. J Immunol 1999;163:6251-6260.

-20 MacDonald KP, Rowe V, Clouston AD, Welply JK, Kuns RD, Ferrara JL, Thomas R, Hill GR: Cytokine expanded myeloid precursors function as regulatory antigen-presenting cells and promote tolerance through il-10producing regulatory t cells. J Immunol 2005;174:1841-1850.

21 Hoechst B, Ormandy LA, Ballmaier M, Lehner F, Kruger C, Manns MP, Greten TF, Korangy F: A new population of myeloid-derived suppressor cells in hepatocellular carcinoma patients induces cd4(+) cd25(+)foxp3(+) t cells. Gastroenterology 2008;135:234-243.

22 Yi H, Guo C, Yu X, Zuo D, Wang XY: Mouse cd11b+gr-1+ myeloid cells can promote th17 cell differentiation and experimental autoimmune encephalomyelitis. J Immunol 2012;189:4295-4304.

23 Poschke I, Kiessling R: On the armament and appearances of human myeloid-derived suppressor cells. Clin Immunol 2012;144:250-268.

24 Filipazzi P, Huber V, Rivoltini L: Phenotype, function and clinical implications of myeloid-derived suppressor cells in cancer patients. Cancer Immunol Immunother 2012;61:255-263.

25 Peranzoni E, Zilio S, Marigo I, Dolcetti L, Zanovello P, Mandruzzato S, Bronte V: Myeloid-derived suppressor cell heterogeneity and subset definition. Curr Opin Immunol 2010;22:238-244.

26 Janols H, Bergenfelz C, Allaoui R, Larsson AM, Ryden L, Bjornsson S, Janciauskiene S, Wullt M, Bredberg A, Leandersson K: A high frequency of mdscs in sepsis patients, with the granulocytic subtype dominating in gram-positive cases. J Leukoc Biol 2014;96:685-693.

27 Poschke I, Mougiakakos D, Hansson J, Masucci GV, Kiessling R: Immature immunosuppressive cd14+hladr-/low cells in melanoma patients are stat3hi and overexpress cd80, cd83, and dc-sign. Cancer Res 2010;70:4335-4345.

28 Gordon IO, Freedman RS: Defective antitumor function of monocyte-derived macrophages from epithelial ovarian cancer patients. Clin Cancer Res 2006;12:1515-1524.

-29 Haile LA, von Wasielewski R, Gamrekelashvili J, Kruger C, Bachmann O, Westendorf AM, Buer J, Liblau R, Manns MP, Korangy F, Greten TF: Myeloid-derived suppressor cells in inflammatory bowel disease: A new immunoregulatory pathway. Gastroenterology 2008;135:871-881, 881 e871-875.

30 Jiao Z, Hua S, Wang W, Wang H, Gao J, Wang X: Increased circulating myeloid-derived suppressor cells correlated negatively with th17 cells in patients with rheumatoid arthritis. Scand J Rheumatol 2013;42:8590.

-31 Yeager ME, Nguyen CM, Belchenko DD, Colvin KL, Takatsuki S, Ivy DD, Stenmark KR: Circulating myeloidderived suppressor cells are increased and activated in pulmonary hypertension. Chest 2012;141:944-952. 
32 Baumgart DC, Metzke D, Schmitz J, Scheffold A, Sturm A, Wiedenmann B, Dignass AU: Patients with active inflammatory bowel disease lack immature peripheral blood plasmacytoid and myeloid dendritic cells. Gut 2005;54:228-236.

33 Duffy A, Zhao F, Haile L, Gamrekelashvili J, Fioravanti S, Ma C, Kapanadze T, Compton K, Figg WD, Greten TF: Comparative analysis of monocytic and granulocytic myeloid-derived suppressor cell subsets in patients with gastrointestinal malignancies. Cancer Immunol Immunother 2013;62:299-307.

-34 Huang A, Zhang B, Wang B, Zhang F, Fan KX, Guo YJ: Increased cd14(+)hla-dr (-/low) myeloid-derived suppressor cells correlate with extrathoracic metastasis and poor response to chemotherapy in non-small cell lung cancer patients. Cancer Immunol Immunother 2013;62:1439-1451.

35 Diaz-Montero CM, Salem ML, Nishimura MI, Garrett-Mayer E, Cole DJ, Montero AJ: Increased circulating myeloid-derived suppressor cells correlate with clinical cancer stage, metastatic tumor burden, and doxorubicin-cyclophosphamide chemotherapy. Cancer Immunol Immunother 2009;58:49-59.

-36 Tang H, Zhong Y, Zhu Y, Zhao F, Cui X, Wang Z: Low responder t cell susceptibility to the suppressive function of regulatory t cells in patients with dilated cardiomyopathy. Heart 2010;96:765-771.

37 Tang TT, Ding YJ, Liao YH, Yu X, Xiao H, Xie JJ, Yuan J, Zhou ZH, Liao MY, Yao R, Cheng Y, Cheng X: Defective circulating cd4cd25+foxp3+cd127(low) regulatory t-cells in patients with chronic heart failure. Cell Physiol Biochem 2010;25:451-458.

38 Meng K, Zhang W, Zhong Y, Mao X, Lin Y, Huang Y, Lang M, Peng Y, Zhu Z, Liu Y, Zhao X, Yu K, Wu B, Ji Q, Zeng Q: Impairment of circulating cd4cd25(+)garp(+) regulatory t cells in patients with acute coronary syndrome. Cell Physiol Biochem 2014;33:621-632.

-39 Thakar M, Patil R, Shukre S, Bichare S, Kadam P, Khopkar P, Ghate M, Paranjape R: Genital tumor growth factor-beta1 levels in hiv-infected indian women are associated with reduced levels of innate antimicrobial products and increased hiv shedding. AIDS Res Hum Retroviruses 2014;30:648-653.

-40 Di Luigi L, Sottili M, Antinozzi C, Vannelli GB, Romanelli F, Riccieri V, Valesini G, Lenzi A, Crescioli C: The vitamin $d$ receptor agonist bxl-01-0029 as a potential new pharmacological tool for the treatment of inflammatory myopathies. PloS one 2013;8:e77745.

41 Niccoli G, Liuzzo G, Montone RA, Crea F: Advances in mechanisms, imaging and management of the unstable plaque. Atherosclerosis 2014;233:467-477.

42 Galkina E, Ley K: Immune and inflammatory mechanisms of atherosclerosis (*). Annu Rev Immunol 2009;27:165-197.

43 Sprague AH, Khalil RA: Inflammatory cytokines in vascular dysfunction and vascular disease. Biochem Pharmacol 2009;78:539-552.

44 Tedgui A, Mallat Z: Cytokines in atherosclerosis: Pathogenic and regulatory pathways. Physiol Rev 2006;86:515-581.

45 Dolcetti L, Peranzoni E, Ugel S, Marigo I, Fernandez Gomez A, Mesa C, Geilich M, Winkels G, Traggiai E, Casati A, Grassi F, Bronte V: Hierarchy of immunosuppressive strength among myeloid-derived suppressor cell subsets is determined by GM-CSF. Eur J Immunol 2010;40:22-35.

46 Turnquist HR, Zhao Z, Rosborough BR, Liu Q Castellaneta A, Isse K, Wang Z, Lang M, Stolz DB, Zheng XX, Demetris AJ, Liew FY, Wood KJ, Thomson AW: Il-33 expands suppressive cd11b+ gr-1(int) and regulatory t cells, including st2l+ foxp3+ cells, and mediates regulatory t cell-dependent promotion of cardiac allograft survival. J Immunol 2011;187:4598-4610.

47 Serafini P, Mgebroff S, Noonan K, Borrello I: Myeloid-derived suppressor cells promote cross-tolerance in b-cell lymphoma by expanding regulatory t cells. Cancer Res 2008;68:5439-5449.

48 Centuori SM, Trad M, LaCasse CJ, Alizadeh D, Larmonier CB, Hanke NT, Kartchner J, Janikashvili N, Bonnotte B, Larmonier N, Katsanis E: Myeloid-derived suppressor cells from tumor-bearing mice impair tgf-beta-induced differentiation of cd4+cd25+foxp3+ tregs from CD4+CD25-Foxp3- T cells. J Leukoc Biol 2012;92:987-997.

49 Nefedova Y, Nagaraj S, Rosenbauer A, Muro-Cacho C, Sebti SM, Gabrilovich DI: Regulation of dendritic cell differentiation and antitumor immune response in cancer by pharmacologic-selective inhibition of the janus-activated kinase 2/signal transducers and activators of transcription 3 pathway. Cancer Res 2005;65:9525-9535.

50 Huang JR, Tsai YC, Chang YJ, Wu JC, Hung JT, Lin KH, Wong CH, Yu AL: Alpha-galactosylceramide but not phenyl-glycolipids induced nkt cell anergy and IL-33-mediated myeloid-derived suppressor cell accumulation via upregulation of egr2/3. J Immunol 2014;192:1972-1981. 